\title{
Introduction
}

This issue of North Carolina Libraries is devoted to examining the current status of some of the many networking activities taking place in our state. The term network is not easy to define. The dictionary definition of an "interrelated or interconnected chain, group or system" does not do full justice to the concept. Specifically, the dictionary definition does not show the dynamic nature of a network, that is, its ability to expand, contract, or change in order to fulfill specific needs. It is this very elasticity and vitality that give the concept of a network its greates potential. Mention the term network to a group of librarians and you will probably get as many different answers as there are people present. Most people would probably first tend to think of the large bibliographic and data base networks such as OCLC, RLIN, BRS, or DIALOG. However, as the 1982 King Research study on networking in North Carolina pointed out, the concept of a network also exists at much smaller levels and in less traditional ways than those just mentioned. The articles in this issue will call attention to the diverse types of networking in North Carolina-from TRLN and LAMBDA to the CLONE project and the AHEC library network.

In this issue, Marge Lindsey outlines the results that have been achieved by the various task force groups of the North Carolina Network Steering Committee. Ruth Katz reports on the results of the first two ZOC (Zone of Cooperation) grants that were selected by her task force group. SOLINET's experimental LAMBDA system is reviewed as an in-house network at the Division of State Library by Eunice Drum and Joe and Denise Sigmon. The potential for public school networking is presented by Mary Holloway. The current progress of the TRLN network, which may become one of the largest in the state, is presented by Joe Hewitt. Lynne Siemers discusses the work of an already existing special library network among the AHEC libraries.

What is the future for networking in our state? Will we develop a vast, integrated, multitype network of libraries or find that our network- ing needs are handled more efficiently by local or regional ZOCs? The answer to these intriguing questions will unfold for us as we continue to examine and experiment with networks. Whatever the final result may be, our current efforts are a good beginning to an exciting future.

\section{John Welch}

Public Library Consultant

Division of State Library

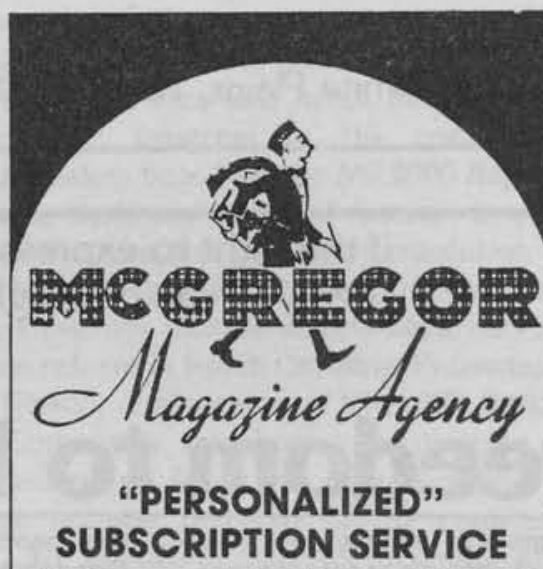

McGregor can simplify complex and time consuming problems of periodical procurement involving research, ordering, payments, renewals and record keeping. Prompt courteous service has been a tradition with McGregor since 1933.

- All domestic and foreign titles

- Title Research

- Prepaid Subscriptions

- Automatic Renewals

- Personal Service Representatives Call or write for catalog today $815734-4183$

MCGREGOR MAGAZINE AGENCY Mount Morris, Illinois 61054 